\title{
Design and Testing of Regenerative Suspension System
}

\author{
Rajat G Jadhav ${ }^{1}$, Sanket S Bhandari ${ }^{2}$, Pawan R Sapkale ${ }^{3}$, Mehul Kumar Dubey ${ }^{4}$, N. Vivekanandan ${ }^{5}$ \\ $1,2,3,48^{\text {th }}$ Semester, Department of Mechanical Engineering, \\ Pimpri Chinchwad college of Engineering, Akurdi, Pune-411044, Maharashtra, India \\ ${ }^{5}$ Assistant Professor, Department of Mechanical Engineering, \\ Pimpri Chinchwad college of Engineering, Akurdi, Pune-411044, Maharashtra, India
}

\begin{abstract}
With the increasing number of vehicle possession and severe hike in consumption, natural fuels which are obviously limited and on the verge of extinction, the area of energy conservation and saving have received great attention from automobile manufacturers and the government all over the world. Usually the vibration energy caused by road roughness when the runs have not being paid attention to and it is wasted through conversion to thermal energy. If the vibration energy can be recovered and converted to other form of energy so as to supply for other devices then the aim of eco-friendly energy saving is reached. This paper consists design and analysis of mechanical regenerative shock absorber in detail. The mechanism of this innovative shock absorber implies use of a simple D.C generator for the conversion of energy possessed by the relative motion between vehicle wheels and the chassis. At the same time, the damping can remove the discomfort caused by the irregular road surface. The regenerated electric power can be recovered through the battery. The analysis of N-66 gears used in the system for lower inertia and better performance was performed on the ANSYS software based on the structure parameters as found by the design calculations. Analysis and calculations prove the viability of this shock absorber.
\end{abstract}

Keywords: Regenerative suspension systems, McPherson Strut, DC Generator, Rack and Pinion assembly.

\section{Introduction}

Fossil fuels are being consumed with very fast rate. Also the cost of fuel is increasing with a very fast rate. Every need of a human being is indirectly related with the cost of fossil fuels like petrol, diesel and other hydrocarbons. So somebody has to work on saving the fuel consumption. A wide experimentation \& work is done on the increment of IC engine efficiency.

So there is a very specific \& precise scope for increasing the average. But there is a wide scope for regeneration of energy like regeneration of breaking system etc. We have decided to work on utilization of suspending mass of a vehicle through regeneration system with the help of a shock absorber. Shock absorbers are having reciprocating motion in it.

Although the reciprocating distance is very low the suspending mass is very high i.e. the mass of total vehicle. When vehicle is on a normal road even then shock absorbers are working due to uneven roads, sudden breaking or sudden acceleration. So this reciprocating motion of shock absorbers can be converted into rotary motion. If a small gearbox is attached to alternator of automobile such that electricity will be generated when shock absorbers will be reciprocating. When vehicle will pass through a dump or pit, that time high energy will be generated through alternator. Battery is connected to the alternator, such that battery will be charged due to suspension system.

Currently the batteries of automobiles are charged by specific alternator which is attached to IC engine shaft. So that the fuel used in automobiles is also consumed for rotating the alternator to charge the battery. This consumption is found to be $4 \%$ of the total consumption. By newly designed suspension regeneration system presently using alternator is detached from the engine and attached to the suspension system. If we install this regeneration system for all 4 wheels then we can generate high amount of electric power. This high amount of electric power can be used for the working of car air conditioner or refrigeration system of vehicles. This suspension system will be mostly useful for heavy compressed vehicles, milk trucks, fire brigade trucks and also those having high requirement of electricity inside it.

Modest savings on battery power create cumulative benefits: For the same travel range, battery weight, recharge times and battery purchase costs are all reduced. If widely adapted in lithium-ion battery powered vehicles, this would lead to a useful drop in the market price of lithium and reduced demands on the power grid, when the batteries are being recharged.

We propose a design plan that converts the mechanical energy in cars to electrical energy much more efficiently than it has been done before. The electricity generated will then be used to recharge the car battery for further use for functioning of the car.

\section{Problem Definition}

The internal combustion engine used in current automobiles has efficiency of around $30 \%$ to $40 \%$. From this small efficiency, apart from generating tractive effort for vehicle movement the engine has to run various systems such as lighting system, air conditioning system, ECU of vehicle, etc. The alternator used to charge battery is directly coupled to engine shaft. As a result of it, the alternators directly or 


\section{International Journal of Science and Research (IJSR) \\ ISSN (Online): 2319-7064 \\ Index Copernicus Value (2013): 6.14 | Impact Factor (2015): 6.391}

indirectly consume brake power obtained at engine shaft with very low efficiency. The amount of energy consumed by the alternator is approximately $4 \%$ of total energy generated. So this creates a situation for us where need to replace the alternator to some system which will not add up to the engine load and also recover the waste energy which is dissipated to the surrounding.

As per research, we could find two such systems which have high energy potential and is not being utilised i.e. brake power and suspension power. Suspension system seem to be more promising so we decided to develop a system which regenerates the energy obtained from the continuous displacement of suspension system. If we couple this system to all four wheels of vehicle, it can fulfil the demand of charging battery. This electricity can later be supplied to other systems.

Currently there is suspension energy regenerating system which works on principles such as hydraulic system, electromagnetic system, pneumatic system, piezoelectric system, etc. But the drawback of these systems is complex construction, difficult to maintain, high cost, less reliability.

Thus, we came up with an idea of developing a suspension energy regenerating system which will make use of simple rack and pinion assembly to convert reciprocating motion in to rotary motion and supplying this rotary motion to a generator after passing through a step up gearbox. In case of electric vehicles, the major problem with them is less distance covered in one full charge of battery. So we can implement this system more efficiently in electric vehicles to enhance the performance of them.

\section{Mechanical Regenerative Suspension System}

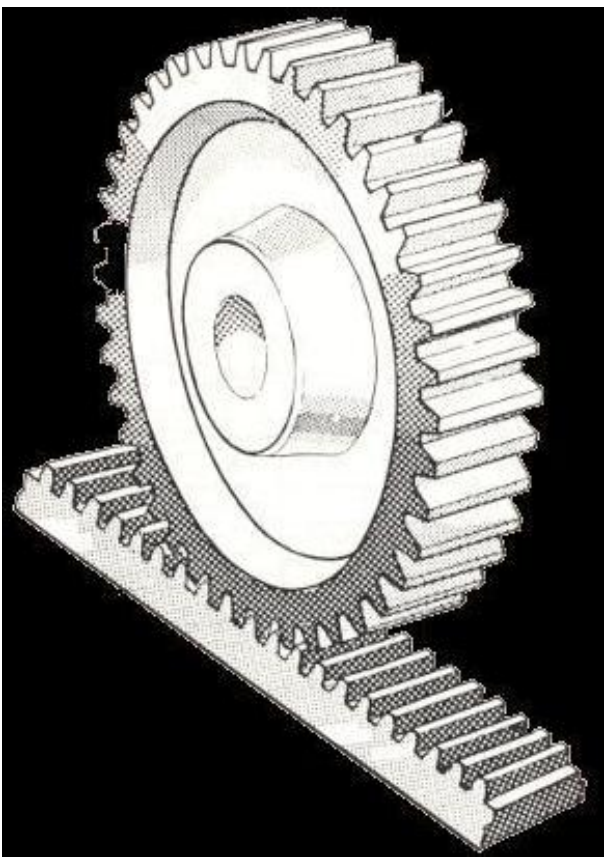

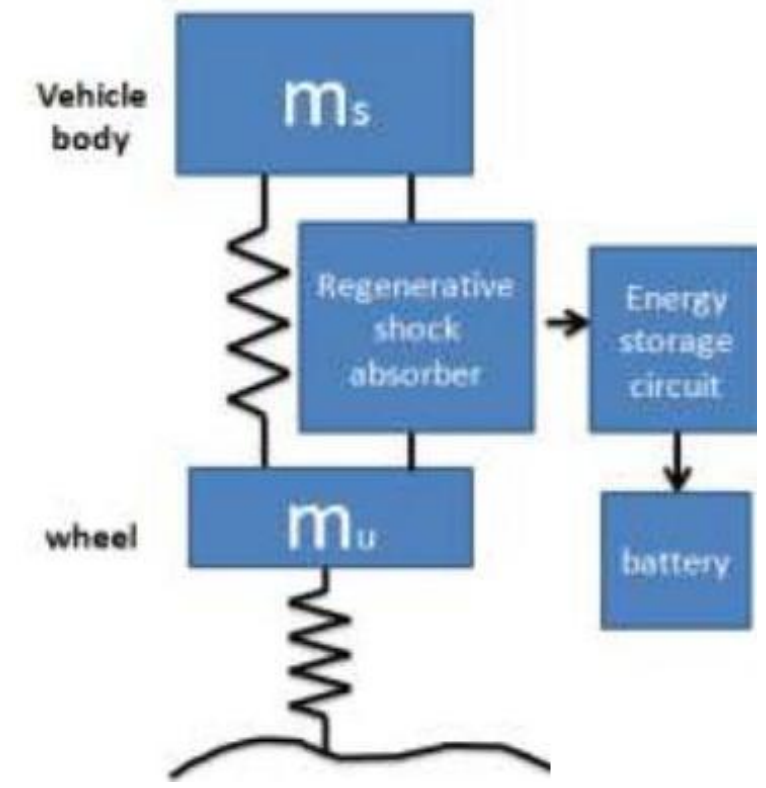

Figure 1: Block Diagram of Mechanical Regenerative System

Mechanical Regenerative system consists of a rack and pinion assembly which will convert the linear motion of wheel to rotary motion. This rotating motion of pinion is then coupled to a reduction gearbox which will increase the angular velocity at output. This high rpm output is then connected to a DC Generator. Each system is separately explained below.

\section{Rack and Pinion Assembly}

A rack and pinion mechanism is used to transform rotary motion into linear motion and vice versa. A round spur gear, the pinion, meshes with a spur gear which has teeth set in a straight line, the rack and pinion is a type of linear actuator that comprises a pair of gears which convert rotational motion into linear motion. A circular gear called "the pinion" engages teeth on a linear "gear" bar called "the rack"; rotational motion applied to the pinion causes the rack to move, thereby translating the rotational motion of the pinion into the linear motion of the rack. For example, in a rack railway, the rotation of a pinion mounted on a locomotive or a railcar engages a rack between the rails and pulls a train along a steep slope.

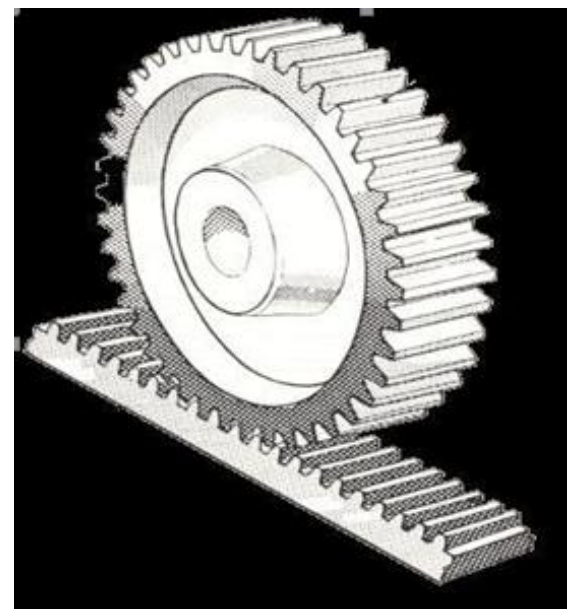

Figure 2: Rack and Pinion Assembly

Volume 5 Issue 6, June 2016 www.ijsr.net 


\section{International Journal of Science and Research (IJSR) \\ ISSN (Online): 2319-7064 \\ Index Copernicus Value (2013): 6.14 | Impact Factor (2015): 6.391}

\section{Generator:}

In electricity generation, an electric generator is a device that converts mechanical energy to electrical energy. A generator forces electric charge (usually carried by electrons) to flow through an external electrical circuit. It is analogous to a water pump, which causes water to flow (but does not create water). The source of mechanical energy may be a reciprocating or turbine steam engine, water falling through a turbine or waterwheel, an internal combustion engine, a wind turbine, a hand crank, compressed air or any other source of mechanical energy. The reverse conversion of electrical energy into mechanical energy is done by an electric motor, and motors and generators have many similarities. Many motors can be mechanically driven to generate electricity, and frequently make acceptable generators.

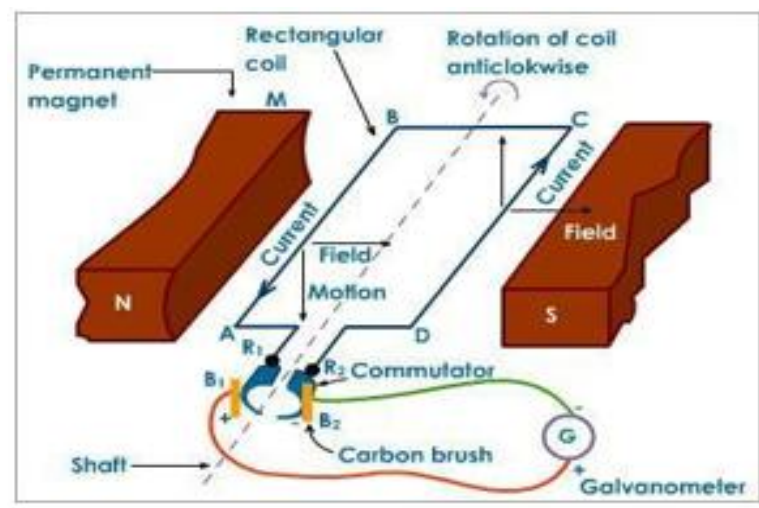

Figure 3: DC Generator

\begin{abstract}
Alternator
Without a commentator, a dynamo becomes an alternator, which is a synchronous singly fed generator. When used to feed an electric power grid, an alternator must always operate at a constant speed that is precisely synchronized to the electrical frequency of the power grid. A DC generator can operate at any speed within mechanical limits, but always outputs direct current.
\end{abstract}

Typical alternators use a rotating field winding excited with direct current, and a stationary (stator) winding that produces alternating current. Since the rotor field only requires a tiny fraction of the power generated by the machine, the brushes for the field contact can be relatively small. In the case of a brushless exciter, no brushes are used at all and the rotor shaft carries rectifiers to excite the main field winding.

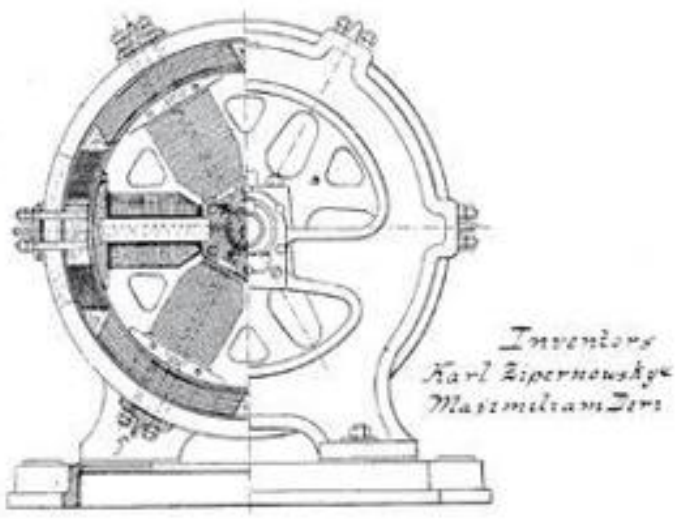

Figure 4: Alternator

\section{Rectifier Circuit}

A rectifier is an electrical device that converts alternating current (AC), which periodically reverses direction, to direct current (DC), which flows in only one direction. The process is known as rectification.

Here in our application the output voltage will vary as per the bump or trough on the way. To convert this non uniform output voltage to uniform DC output, rectifier circuit is used.

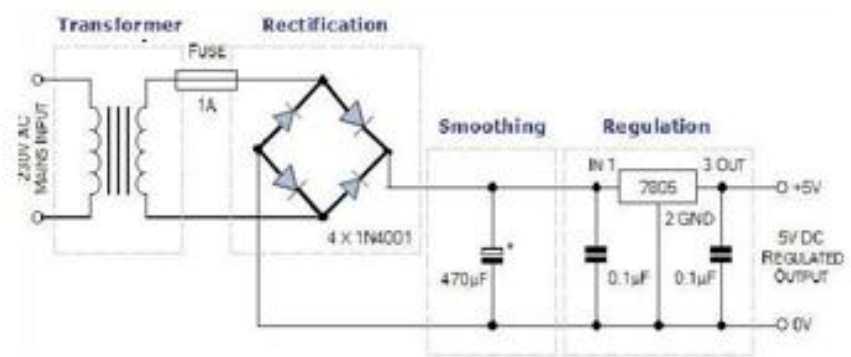

Figure 5: Rectifier Circuit

\section{Design}

Generator $30 \mathrm{rpm} / 5$ watt

Consider for safety $45 \mathrm{rpm} / 5$ watt

$\mathrm{T}=1.591 \mathrm{Nm}$

\section{Assumptions:}

Vertical travel of the suspension system is $5 \mathrm{~mm}$ in every $1 \mathrm{~m}$ of vehicle travel.

Minimum velocity of vehicle is considered as $20 \mathrm{kmph}$.

$20 \mathrm{kmph}$ in $\mathrm{m} / \mathrm{s}$ is equal to $5.55 \mathrm{~m} / \mathrm{s}$. considering

Gear ratio $=5$

$\omega(\mathrm{p})=4.71 \mathrm{rad} / \mathrm{sec}$

For Rack and Pinion pair, diameter of pinion is calculated as, $5.55 \mathrm{~m}$ in $1 \mathrm{sec}$

So $1 \mathrm{~m}$ in ?sec.

$=0.1801 \mathrm{sec}$

Linear Velo of Pinion

$=\frac{\text { Vertical Travel of suspension system }}{\text { Time taken by wehicle to travel } 5 \mathrm{~mm}}$

$=0.005 / 0.1801$

$=0.0277 \mathrm{~m} / \mathrm{s}$.

$\mathrm{V}=\mathrm{r} \omega / 5$

$\mathrm{r}=30 \mathrm{~mm}$

So, pitch circle diameter of pinion is $60 \mathrm{~mm}$,

Taking standard module as $1.5 \mathrm{~mm}$, Number of teeth on pinion is 40 .

Volume 5 Issue 6, June 2016 www.ijsr.net 


\section{International Journal of Science and Research (IJSR) \\ ISSN (Online): 2319-7064}

Index Copernicus Value (2013): 6.14 $\mid$ Impact Factor (2015): 6.391

\section{Design for Reduction Gear Pair:}

Taking diameter for pinion as, $30 \mathrm{~mm}$

And taking diameter for gear wheel as $150 \mathrm{~mm}$.

From the motor specifications,

$\mathrm{T}=1.591 \mathrm{Nm}$

$\mathrm{F}=\mathrm{T} / \mathrm{r}$

So, $\mathrm{F}=106.10 \mathrm{~N}$

This force is tangential force acting on pinion

Taking face width $=10 \mathrm{x}$ Module of gear

$=10 \times 1.5$

$=15 \mathrm{~mm}$

Since $\mathrm{I}<8$, selecting material for the pinion as $\mathrm{C} 45$ $\cdots$

And for gear wheel C35Mn75

$\mathrm{S}$ (ut) of $\mathrm{C} 45=657.27 \mathrm{~N} / \mathrm{mm}^{2}$

$\mathrm{S}(\mathrm{yt}) \mathrm{of} \mathrm{C} 45=353.96 \mathrm{~N} / \mathrm{mm}^{2}$

Hardness $=229 \mathrm{BHN}$

Allowable bending stress for pinion,

$\sigma(b)=\mathrm{S}(\mathrm{ut}) / 3$

$=219.09 \mathrm{~N} / \mathrm{mm}^{2}$

Pitch line velocity will be less than $10 \mathrm{~m} / \mathrm{s}$

$\mathrm{V}=(\mathrm{r} \omega)$

$=0.015 \times 2 \pi \times 45$

$=260$

$c(v)=3 /(3+v)$

$=0.977$

Effective load acting on the gear pair is,

$P(e f f)=\frac{C(s) * F}{\mathrm{C}(\mathrm{v})}$

For Medium shock loading, Service factor $\mathrm{C}(\mathrm{s})=1.5$

$\mathrm{P}($ eff $)=162.89 \mathrm{~N}$.

Lewis equation for Beam strength is given by,

$S_{b}=m b \sigma_{b} Y$

Taking Y, Lewis Form Factor, for $20^{\circ}$ full depth involute as 0.314

$\mathrm{S}_{\mathrm{b}}=$ FOS $\times \mathrm{P}_{\mathrm{eff}}$

FOS $=1.5$ for medium shock load

$\mathrm{m} \times 10 \mathrm{~m} \times 220 \times 0.314=1.5 \times 162.89$ $\mathrm{m}=0.6 \mathrm{~mm}$

This module is not standard, so taking standard module as $1.5 \mathrm{~mm}$,

Checking the gear pair for wear strength:

$\mathrm{S}(\mathrm{w})=\mathrm{bQD}(\mathrm{p}) \mathrm{K}$,

Where, $\mathrm{K}=$ Load factor.

$\mathrm{K}=0.16 *(\mathrm{BHN} / 100)^{2}$

$\mathrm{Z}(\mathrm{p})=20, \mathrm{Z}(\mathrm{g})=100$

$\mathrm{Q}=2 \mathrm{Z}(\mathrm{g})$

$\mathrm{Q}=1.67$

$\mathrm{K}=0.8390$

$\mathrm{S}(\mathrm{w})=630 \mathrm{~N}$

$\mathrm{FOS}=630.50 /(1.5 \times 162.89)=1.8$

So the available FOS is greater, therefore we can say that the design is safe.

\section{Number of Teeth on Rack:}

Total vertical travel of wheel $=6$ inch

Considering the PCD of an imaginary gear=6inch

Dia of that gear=1.9inch

i.e $48.26 \mathrm{~mm}$

We know the module of rack and Pinion pair, $\mathrm{m}=1.5 \mathrm{~mm}$

No. of teeth on rack $=33$ teeth.

Design of Shaft:

Shaft is designed according to ASME code.

$\mathrm{T}($ Per $)=0.3 \times \mathrm{S}(\mathrm{yt})$

$=0.18 \times \mathrm{S}(\mathrm{ut})$

Select the lower value from the two.

Power $=5$ watt,

$\mathrm{Rpm}=30$,

Commonly used material for shaft is C35

Properties of C35

$\mathrm{S}(\mathrm{ut})=560 \mathrm{Mpa}$

$\mathrm{S}(\mathrm{yt})=305 \mathrm{Mpa}$

For heavy shock load

$\mathrm{K}(\mathrm{b})=$ Coefficient for bending load $=2.5$

$K(t)=$ Coefficient for torsional load $=2.25$

$\mathrm{T}($ Per $)=0.3 \mathrm{x}$

$\mathrm{S}(\mathrm{yt})=91.23 \mathrm{Mpa}$

Volume 5 Issue 6, June 2016

www.ijsr.net

Licensed Under Creative Commons Attribution CC BY 


\section{International Journal of Science and Research (IJSR) \\ ISSN (Online): 2319-7064}

Index Copernicus Value (2013): 6.14 $\mid$ Impact Factor (2015): 6.391
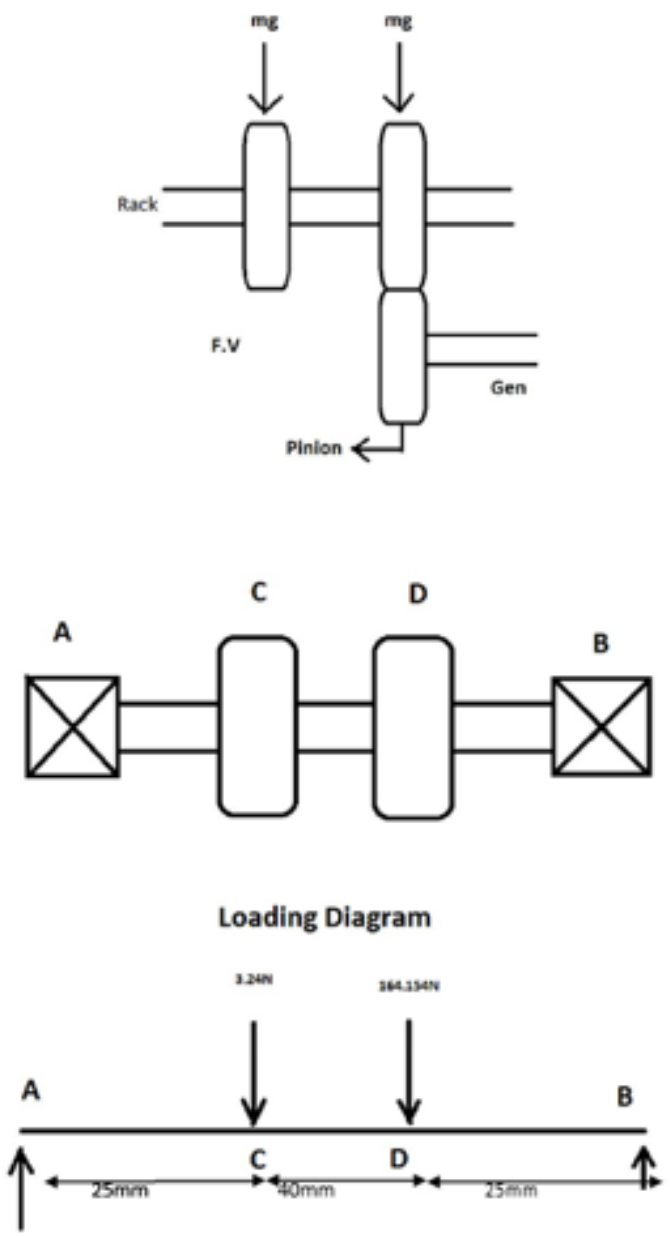

R.

Figure 6: Loading Diagram

Taking moment about $\mathrm{A}=0$,

Reaction at point B is $119.45 \mathrm{~N}$

Summation of all vertical forces $=0$

Reaction at point $\mathrm{A}=47.93 \mathrm{~N}$

Bending moments at points,

Bending moment at $\mathrm{A}=-0.51 \mathrm{Nmm}$

Bending moment at $\mathrm{B}=0.75 \mathrm{Nmm}$

Bending moment at $\mathrm{C}=-1198.25 \mathrm{Nmm}$

Bending moment at $\mathrm{D}=2986.25 \mathrm{Nmm}$

Torque $=1590 \mathrm{Nmm}$

Equivalent Torque is given by

$$
\mathrm{Te}=\sqrt{(\mathrm{Kb} * \mathrm{M})^{2}+(\mathrm{Kt} * \mathrm{~T})^{2}}
$$

$$
=8278.53 \mathrm{Nmm}
$$

By using torsion equation as,

$$
\frac{\mathrm{Te}}{\mathrm{I}}=\frac{\tau}{\mathrm{r}}
$$

So, diameter $\mathrm{d}=7.73 \mathrm{~mm}$

Thus, taking standard diameter as $10 \mathrm{~mm}$.

\section{Design Results}
A. Generator Specifications $5 \mathrm{~W}$ atts and 30rpm

B. Rack and Pinion Pair Specifications

Rack;

Length=6inch $(152.4 \mathrm{~mm})$

No of teeth $=33$

Module $=1.5 \mathrm{~mm}$

Pinion;

Module $=1.5$

No of teeth $=20$

C. Reduction Gear Pair (Spur);

Reduction ratio $=5$

Module $=1.5$

No of teeth on pinion $=20$

Material used for pinion $=\mathrm{C} 45$

No of teeth on gear $=100$

Material used for gear $=\mathrm{C} 35 \mathrm{Mn} 75$

Material Used $=$ C 35

Diameter $=10 \mathrm{~mm}$

\section{CAD Model}

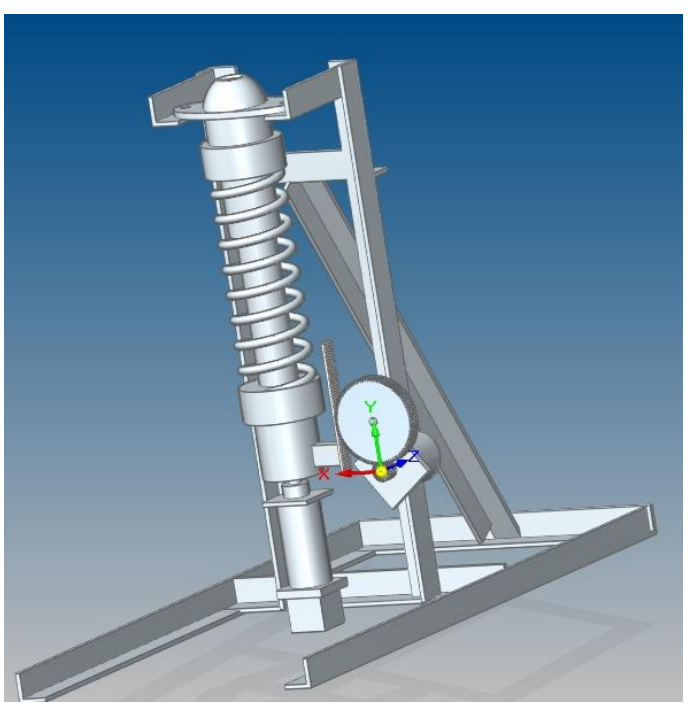

Figure 7: CAD Model

\section{Design Modification}

For better efficiency, lesser weight and inertial losses, Nylon 66 was considered as a replacement to the metal gear. Nylon66 would also give lesser losses due to less mass moment of inertia. As per the standard mechanical properties of Nylon66, the strength validation of gears was done on ANSYS

\section{Results}

During testing it was found that on operating the piston on $3 \mathrm{Bar}$ pressure that is equivalent to half of total weight of vehicle on full load, the generator was able to generate $3 \mathrm{Watt}$ of power. This system if installed to all the wheels of vehicle will generate $12 \mathrm{~W}$ atts of power which is enough to charge the automobile battery. 


\section{International Journal of Science and Research (IJSR) \\ ISSN (Online): 2319-7064}

Index Copernicus Value (2013): 6.14 | Impact Factor (2015): 6.391

\section{Prototype}

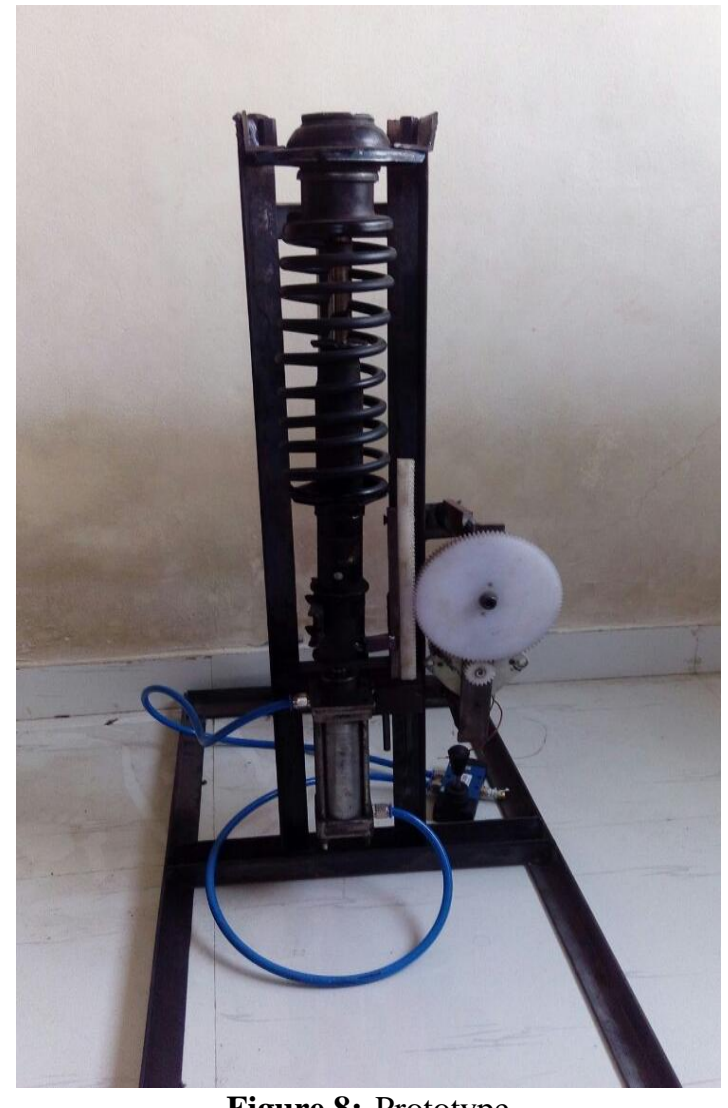

Figure 8: Prototype

\section{Conclusion}

This paper has discussed the development of a mechanical regenerative suspension system. The objectives of this project was to develop the system which would harvest the energy in the suspension system and also be simple for construction and maintenance. It was also necessary to check whether output of the system is worth the cost of design and implementation. Both the objectives were met. By keeping the track of measured output it was concluded that if the system is installed on all wheels of an automobile it will generate output equivalent to $12 \mathrm{Watt}$. This will be enough to independently charge the battery.

This project also has certain limitations such as it has certain space constraints. The system should acquire minimum space and should not hamper the damping capacity of the suspension system. The system was designed to generate 4 Watts of output but the actual system generated 3 Watts of output which was less than the expected due to losses such as frictional loss and alignment loss.

The system which we have designed in this project is suitable for the vehicles where sufficient space is available for accommodating the parallel suspension and regenerative system. We are in the era where the companies are keen on making system compact by using advanced direct conversion devices. Here in our system we can place the regenerative system inside the damper. This will lead to a compact design and lesser load on suspension. As a future scope we can completely replace the conventional damper by mechanical generator and the vibration damping can be provided by the resistance to motion by the generator. This will lead to total vibration energy conversion and better results.

\section{References}

[1] PSG Design Data Book, faculty of mechanical engineering, PSG College of Technology.

[2] Design of Machine Elements, V.B.Bhandari, Tata McGraw Hill publications.

[3] Electrical technology vol.2, B.L.Thareja, S. Chand Publications.

[4] "A Review on Energy-Regenerative Suspension Systems for Vehicles", By Zhang Jin-qiu, Peng Zhi-zhao, Zhang Lei, Zhang Yu

[5] "Vehicle Energy Dissipation Due to Road Roughness", By Steven A. Velinsky and Robert A. White

[6] "McPherson suspension system - a review", By Prof.S.C.Jain, Dr.PushpendrakumarSharma, DharaVadodaria

[7] "Power Generating Shock Absorber", By Meghraj P. Arekar, SwapnilShahade.

[8] "Regenerative Shock Absorber", By Sethu Prakash S, Nidhin Abraham Mammen, Steve John, Varughese Punnoose Kochuparackal, Tobin Thomas.

[9] "Electricity Generation Due to Vibration of Moving Vehicles Using Piezoelectric Effect", By Mukti Nath Gupta, Suman and S.K. Yadav.

[10] "Development of Mechanism for Recovery of Energy of Suspension System", By Mr. SwapnilKamthe, Mr. Rahul Kadam, Mr. AniketDhore, Mr. ShivkumarFalmari, Prof.SubhashGhadve, Prof.MukeshChaudhari.

[11] "Power Generation through Rack \& Pinion in Suspension System for an Automobile", By G.P.Dhalwar, T.A.Jadhav.

[12] "Energy Recuperation in Automotive Active Suspension Systems with Linear Electric Motor", By Antonin Stribrsky, Katerina Hyniova, Jaroslav Honcu and Ales Kruczek

[13]Fig 1; Fig 2; Fig 3; Fig 4; Fig 5 https://www.google.co.in/imghp?hl=en\&tab=wi\&ei=lcd OV_amCcnL0gSm9b2gBA\&ved=0EKouCBMoAQ

[14] http://wikipedia.org./wiki/McPhersonstrut

[15] www.sciencedirect.com/recentpapersonregenerativesusp ensionsystem

[16] http://google.co.in/search/regenerativesuspensionsystem 